\title{
PEMANFAATAN MACROMEDIA FLASH 8 SEBAGAI MEDIA PEMBELAJARAN MATA KULIAH BAHASA INGGRIS PADA FKIP UNIVERSITAS DEHASEN BENGKULU
}

\author{
Heni Kusnita Sari ${ }^{1,}$ Yupianti, ${ }^{2}$ \\ ${ }^{1}$ Dosen Tetap Program Studi Informatika Fakultas Ilmu Komputer Universitas Dehasen Bengkulu \\ Jl. Meranti Raya No. 32 Kota Bengkulu 38228 Telp. (0736) 22027, 26957 Fax. (0736) 341139; e-mail: \\ henikusnitasari74@gmail.com ${ }^{1}$, yupiantiprana@gmail.com ${ }^{2}$
}

\begin{abstract}
The develoment of technology is needed to support and help the institution, school, or college, as well as in decision-making. The develoment of today's technologi have influenced every aspect of human life and is necessary as a means of support that can support the right information, quickly and accurately. Writing this research aims to improve the delivery of an FKIP department PTIK Universitas Dehasen Bengkulu city, So that it can provide a new atmosphere in the teaching and learning quickly and accurately. So with this, multimedia as a means to convey the material to any student that student do not feel bored in receiving lesson given by the lecturer of FKIP department PTIK University Dehasen Bengkulu city can create better result in the delevery of the lesson because in combining text, graphics, animation, audio, images. Based on the result of the Media Learning Englishat Fkip University Dehasen Bengkulu city, it can be concluded with the media Learning English At FKIP University Dehasen Bengkulu city we can assist teachers in preseting the material more easily and understand each of te students well.
\end{abstract}

Keywords: Media, Learning, English Lecture

Intisari--Perkembangan Teknologi sangat mendukung dan dibutuhkan untuk membantu lancarnya dalam instansi, sekolah, atau perguruan tinggi, begitu juga dalam pengambilan keputusan. Perkembangan teknologi saat ini telah mempengaruhi segala bidang kehidupan manusia dan diperlukan sebagai sarana pendukung yang dapat menunjang informasi yang tepat, sepat dan akurat.

Penulisan karya ilmiah ini bertujuan untuk penyampaian suatu mata kuliah di FKIP PTIK Universitas Dehasen Bengkulu, sehingga bisa memberikan suasana baru dalam belajar mengajar dengan secara tepat, cepat dan akurat.

Maka dengan ini, multimedia sebagai salah satu sarana untuk menyampaiakan suatu materi kepada setiap Mahasiswa agar para Mahasiswa tidak merasa bosan dalam menerima pelajaran yang diberikan oleh Bapak dan Ibu Dosen, yang dapat menciptakan hasil yang lebih bagus dalam penyampaian pelajaran karena didalamnya mengkombinasikan teks, grafik, audio, gambar. Berdasarkan dari hasil pembuatan Media Pembelajaran Mata Kuliah Bahasa Inggris Pada FKIP Universitas Dehasen Bengkulu Menggunakan Macromedia Flash 8, dapat diambil kesimpulan dengan adanya Media Pembelajaran Mata Kuliah Bahasa Inggris Pada Fkip Universitas Dehasen Bengkulu Menggunakan Macromedia Flash 8 kita dapat membantu Dosen dalam menyampaikan suatu materi dengan lebih mudah dan dipahami setiap Mahasiswa dengan baik.

Kata Kunci : Media, Pembelajaran,Kuliah Bahasa Inggris

\section{PENDAHULUAN}

Pemanfaatan komputer sebagai alat kerja bantu manusia, khususnya sebagai media pengolah data, baik yang berskala besar maupun skala kecil, sekarang ini mengalami perkembangan positif yang sangat besar. Hal ini dapat dikarenakan oleh faktor pendorong dan faktor keunggulan dari komputer itu sendiri. Faktor pendorong dapat berupa kemajuan teknologi di bidang informasi, serta kebutuhan dan tuntutan manusia yang menginginkan semua pekerjaan dan kebutuhannya dapat dilaksanakan dengan aman, cepat dan akurat, sedangkan komputer memiliki keunggulan tersebut. Walaupun masih banyak kendala dan kelemahan yang diciptakan oleh sistem komputer itu sendiri, dengan memperbaiki keterbatasan dan kelemahan yang ada, proses komputerisasi dimasa sekarang dan masa mendatang tetap berjalan.

Komputerisasi adalah pemanfaatan komputer secara benar dan semaksimal mungkin dan bukan sekedar pengganti mesin ketik saja. Hal ini harus ditunjang oleh hardware (perangkat keras), software (perangkat lunak), dan brainware (operator / pemakai komputer). Untuk masa sekarang ini, ketiga faktor tersebut saling berkaitan dan harus terpenuhi semua, agar komputer dapat menjalankan tugas dan fungsinya secara baik dan benar.

\section{LANDASAN TEORI}

\section{A. Media Pembelajaran}

Media pembelajaran adalah solusi yang dapat digunakan oleh Dosen dalam mengajar. Dengan media pembelajaran Dosen dapat menjelaskan suatu materi dengan model, foto, atau video tentang objek yang dijelaskan Sejalan dengan berkembangnya ilmu dan teknologi komputer dewasa ini, maka penggunaan media 
pembelajaran yang dapat memberikan aspek multimedia adalah salah satu alternatif yang dapat meningkatkan pemahaman siswa serta dapat lebih menarik minat siswa untuk belajar. Multimedia mempunyai arti tidak hanya integrasi antara teks dan grafik sederhana saja tetapi dilengkapi dengan suara dan animasi. Jadi, sambil mendengarkan penjelasan, dapat melihat gambar, animasi maupun membaca penjelasan dalam bentuk teks. (Deny Satria Wicaksono : 2011)

\section{B. Pengertian Komputer}

Menurut Sutarman (2009 : 3), Komputer adalah suatu alat elektronik yang mampu melakukan beberapa tugas menerima input, memproses input sesuai dengan programnya, menyimpan perintah-perintah dari hasil pengolahan dan menyediakan output dalam bentuk informasi. Menurut Daryanto (2004 : 11), Kata "komputer" berasal dari bahasa Inggris "to computer", yang berarti menghitung. Sedangkan "computer" berarti alat penghitung. Kemudian kata komputer tersebut diterjemahkan ke dalam bahasa Indonesia menjadi komputer. Berdasarkan sifat-sifat yang dimiliki. Komputer dapat didefenisikan sebagai peralatan elektronik yang bekerja secara koordinatif dan integratif berdasarkan program, dapat menerima masukan berupa data, mengolahnya dalam memori, dan menampilkan hasil berupa informasi.

\section{Tinjauan Umum Tentang Mata Kuliah}

Dalam mata kuliah wajib universitas Bahasa Inggris 2, yang didalamnya menjelaskan materi-materi sebagai berikut : Speaking, Grammar, Reading, Listening, Writing. Sesuai dengan batasan masalah pembelajaran yang akan dibahas yaitu tentang Skill Listening. Skill listening merupakan keterampilan reseptif yang perlu dikembangkan untuk membantu Mahasiswa memahami apa yang mereka dengar atau ketika mereka berkomunikasi dengan orang lain. Selain itu, tes mendengarkan sekarang termasuk dalam ujian semesteran Mahasiswa. Pada kenyataannya, hanya beberapa saja upaya yang dilakukan Dosen untuk memeriksa atau bahkan untuk mengembangkan keterampilan mendengarkan siswa jika membandingkan dengan keterampilan lainnya. (Galuh Puspita Ariputri : 2015)

\section{Macromedia flash 8}

Menurut Priyanto (2011 : 18) Macromedia Flash adalah program untuk membuat animasi dan aplikasi web professional. Macromedia Flash telah berubah nama menjadi adobe Flash, akuisisi ini pun bisa jadi merupakan pertanda bahwa prospek pembuatan animasi menggunakan Flash akan semakin baik. Software keluaran macromedia ini merupakan program untuk mendesain grafis animasi yang sangat populer dan banyak digunakan desainer grafis. Selain itu aplikasi ini juga dapat digunakan untuk memuat animasi logo, movie, game, pembuatan navigasi pada situs web, banner, tombol animasi, menu interaktif, interaktif form isian, screen server, dan pembuatan situs web atau pembuatan aplikasiaplikasi web lainnya.

\section{METODOLOGI PENELITIAN}

\section{A.Subjek Penelitian}

Cikal bakal Universitas Dehasen Bengkulu adalah Sekolah Tinggi Manajemen Informatika dan Komputer (STIMIK) Dehasen dan Sekolah Tinggi Ilmu Ekonomi (STIE) Dehasen serta Akademi Teknologi Pertanian (ATP) Dehasen yang didirikan oleh Yayasan Dehasen di Bengkulu. Berdasarkan Keputusan Menteri Pendidikan Nasional Nomor 39/D/O/2008 tanggal 17 Maret 2008 yang merupakan penggabungan dan pengembangan STMIK Dehasen, STIE Dehasen dan ATP Dehasen, kemudian ditetapkan menjadi Universitas Dehasen Bengkulu. Univ ersitas ini bernama Universitas Dehasen Bengkulu dan disingkat Unived, Universitas Dehasen Bengkulu berkedudukan di Bengkulu. Dan dasar dari Universitas Dehasen Bengkulu adalah Pancasila, UndangUndang Dasar 1945 serta kaidah moral dan keilmuan.

\section{HASIL DAN PEMBAHASAN}

\section{A. Hasil Rancangan Program}

Aplikasi Media Pembelajaran Bahasa Inggris Pada FKIP Universitas Dehasen Bengkulu menggunakan Macromedia Flash 8 yang digunkan untuk membantu 
siswa dan Dosen dalam kegiatan belajar mengajar yang selama ini masih masih manual yaitu menggunakan buku dan papan tulis, Aplikasi ini terdiri dari dari Menu Pembuka, Menu Utama, Menu Standar Kompetisi dan Kompetisi Dasar, Menu Materi, Menu Latihan dan Penutup.

\section{Menu Pembuka}

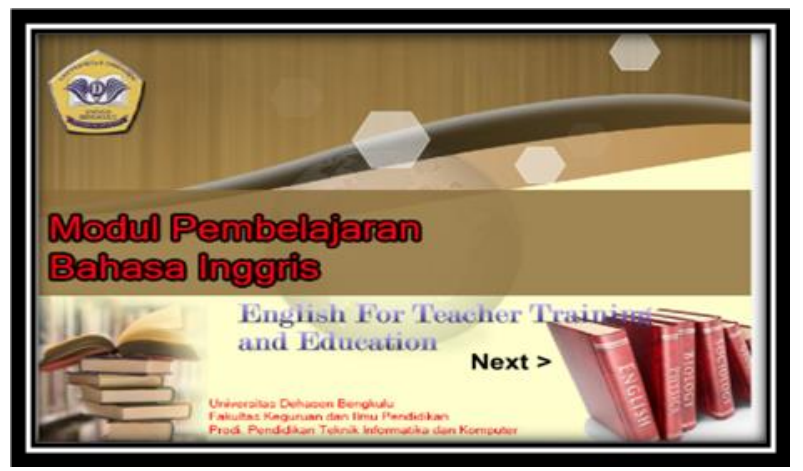

Gambar 1 Rancangan Menu Pembuka

Menu Pembuka adalah tampilan pembuka sebagai tanda bahwa program dimulai. Menu Pembuka berisi tema, gambar, logo Universitas di sudut kanan atas, tulisan animasi suara, dan tombol Next di sudut kanan bawah untuk melanjutkan ke Menu berikutnya.

\section{Menu Utama}

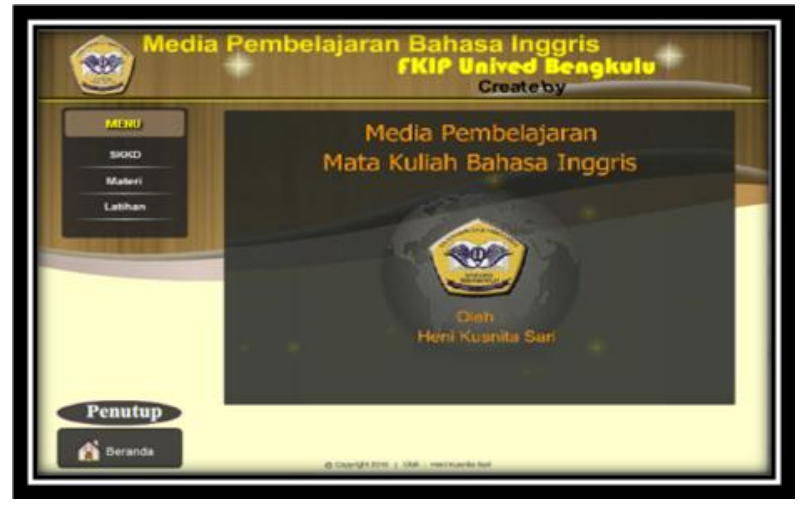

Gambar 2. Rancangan Menu Utama

Tampilan Menu Utama merupakan tampilan dimana pengguna dapat memilih tombol-tombol untuk melanjutkan ke tahap berikutnya seperti ke Menu Materi, Menu Latihan Menu SKKD Menu Penutup dan Menu Beranda untuk kembali ke menu sebelumnya.

Standar Kompetisi Dasar dan Kompetisi Dasar

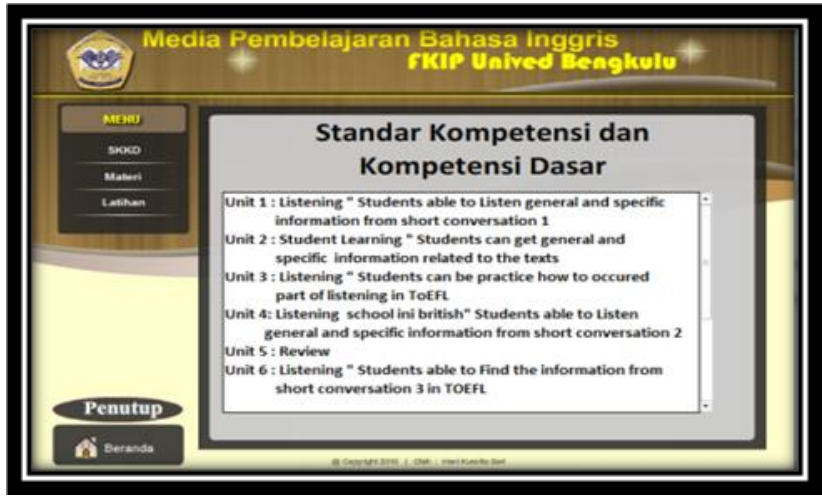

Gambar 3 Standar Kompetisi Dasar dan Kompetisi

Dasar

Menu Kompetisi Dasar dan Kompetisi Dasar ini menjelaskan materi-materi mata kuliah Bahasa Inggris pada Skill Listening dan Reading yang dibahas pada prodi PTIK Semester II. Dan terdapat tombol beranda untuk kembali ke menu utama.

\section{Menu Materi}

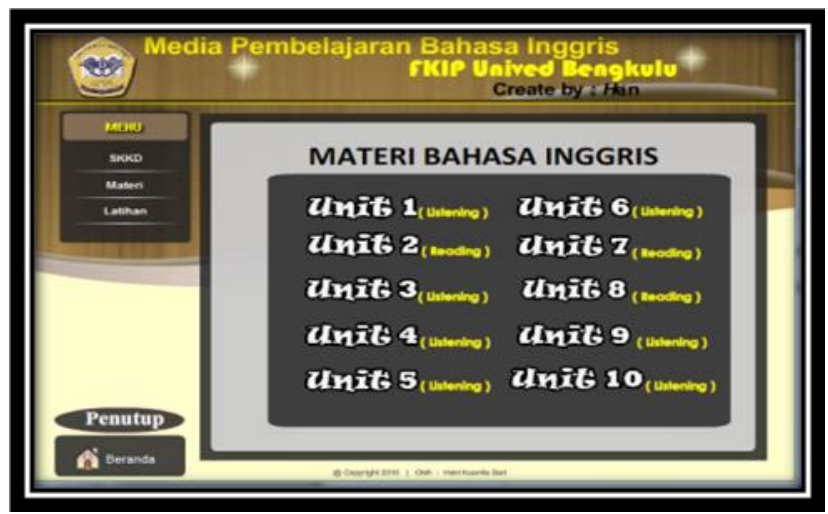

Gambar 4 Rancangan Menu Materi

Menu Materi menampilkan materi-materi yang terdiri dari tombol-tombol materi dari unit 1 sampai dengan I 10.

\section{Rancangan Materi Unit 1}

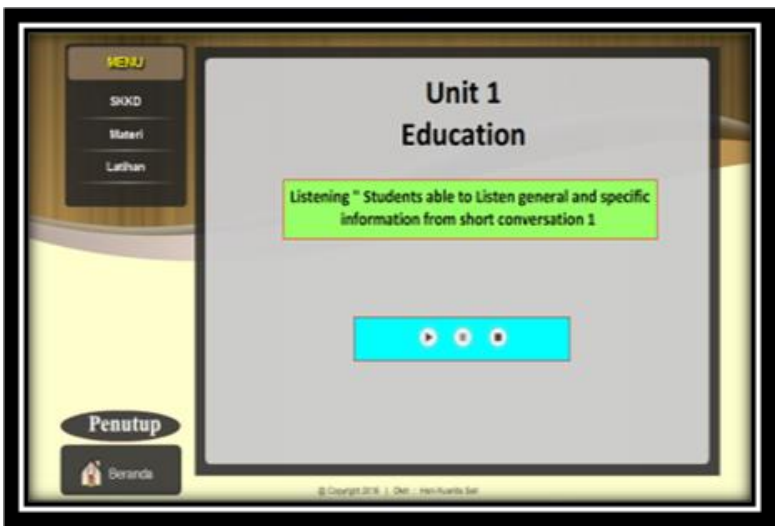

Gambar 5 Rancangan Materi Unit 1 
Menu yang berisi penjelasan materi Listening, dan terdapat tombol-tombol Pause, Play dan Stop.

\section{Rancangan Materi Unit 2}

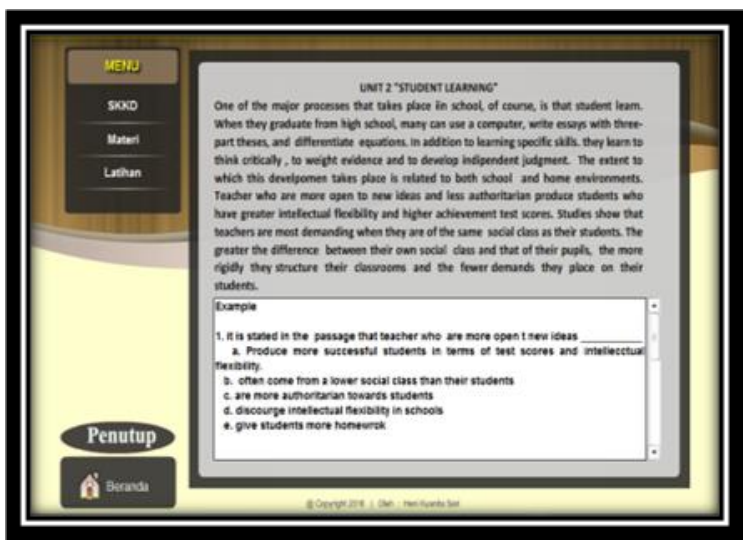

Gambar 6 Rancangan Materi Unit 2

Menu yang berisi Penjelasan Reading pada Materi Unit 2, terdapat menu materi di sisi kiri untuk kembali ke menu materi Unit 1 sampai dengan Unit 10, terdapat Menu Penutup, dan Tombol Beranda untuk kembali ke menu Utama.

\section{Rancangan Materi Unit 3}

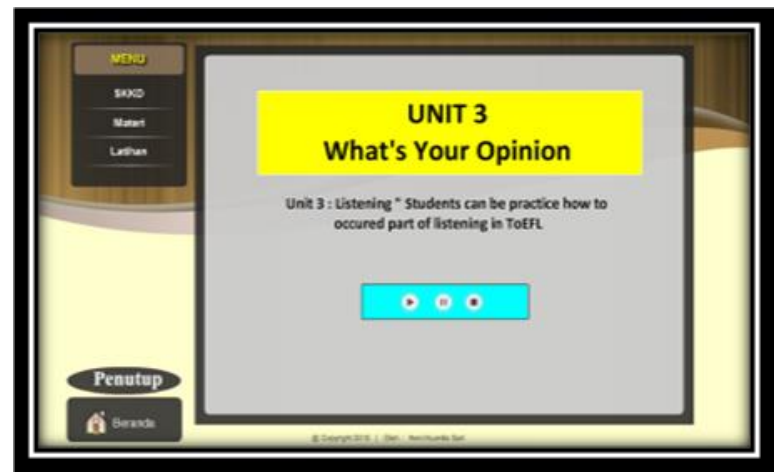

Gambar 7 Rancangan Materi Unit 3

Menu yang berisi penjelasan materi Listening, dan terdapat tombol tombol Pause, Play dan Stop. dan terdapat menu Materi disisi kiri penjelasan materi untuk kembali

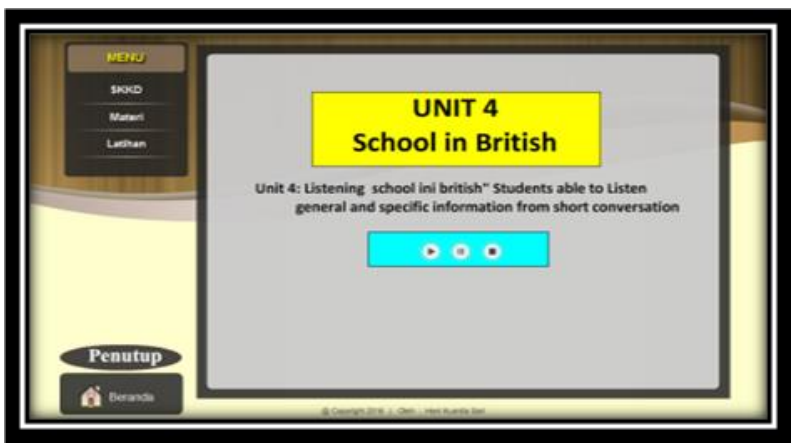

Gambar 8 Rancangan Materi Unit 4
Menu masing-masing unit 1 sampai dengan Unit10 dan terdapat tombol Beranda untuk kembali ke menu Utama.

\section{Rancangan Materi Unit 5}

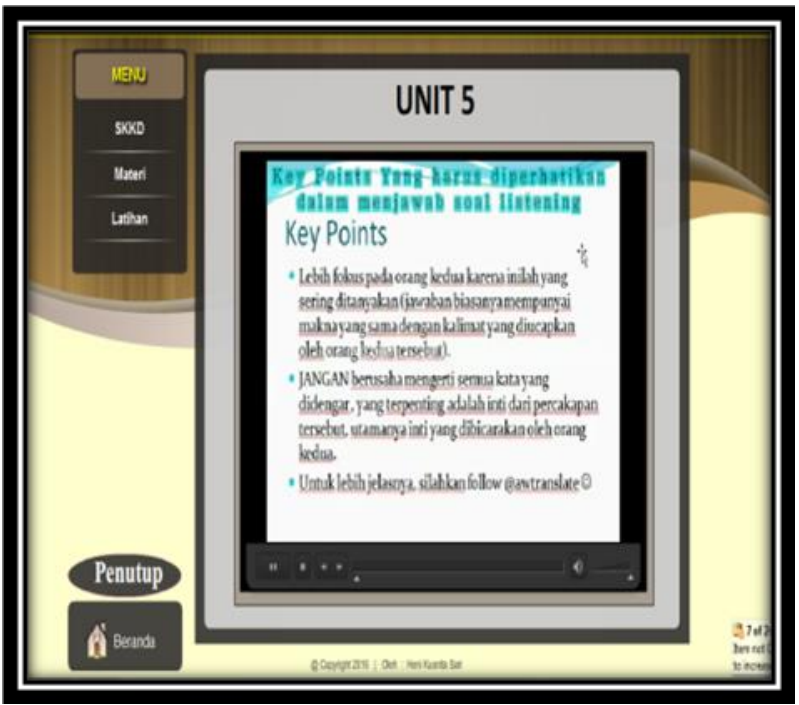

Gambar 9 Rancangan Materi Unit 5

Menu yang berisi penjelasan materi Listening Unit 5, terdapat tombol-tombol Pause, Play dan Stop. dan terdapat menu Materi disisi kiri penjelasan materi untuk kembali ke menu masing-masing unit 1 sampai dengan 10 dan terdapat tombol Beranda untuk kembali ke menu Utama.

\section{Rancangan Materi Unit 6}

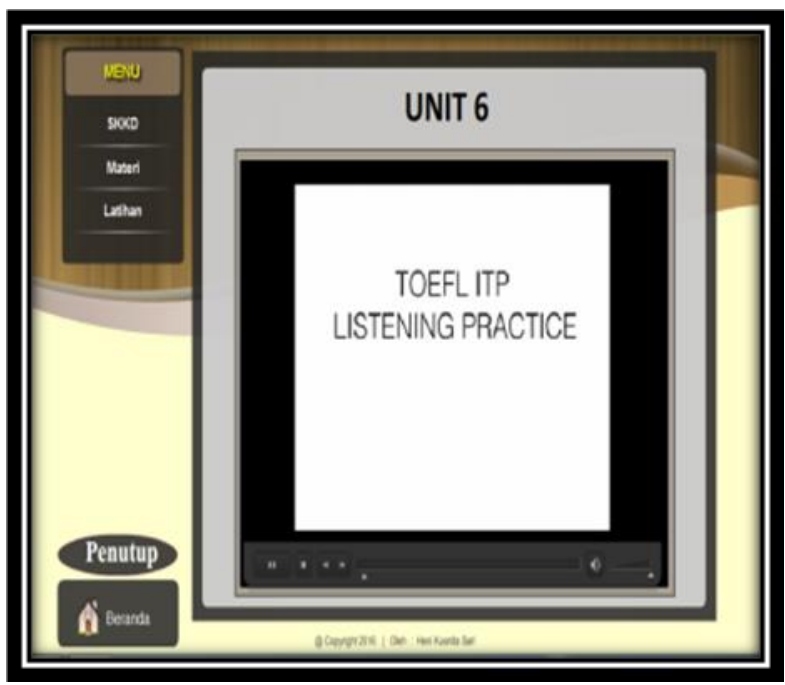

Gambar 10 Rancangan Materi Unit 6

Menu yang berisi penjelasan materi Listening Unit 6, terdapat tombol-tombol Pause, Play dan Stop. dan terdapat menu Materi disisi kiri penjelasan materi untuk kembali ke menu masing-masing 1 sampai dengan 10 dan terdapat tombol Beranda untuk kembali ke menu Utama.

Pemanfaatan Macromedia Flash 8 sebagai Media Pembelajaran Mata Kuliah Bahasa ISSN 1858 - 2680 


\section{Rancangan Materi Unit 7}

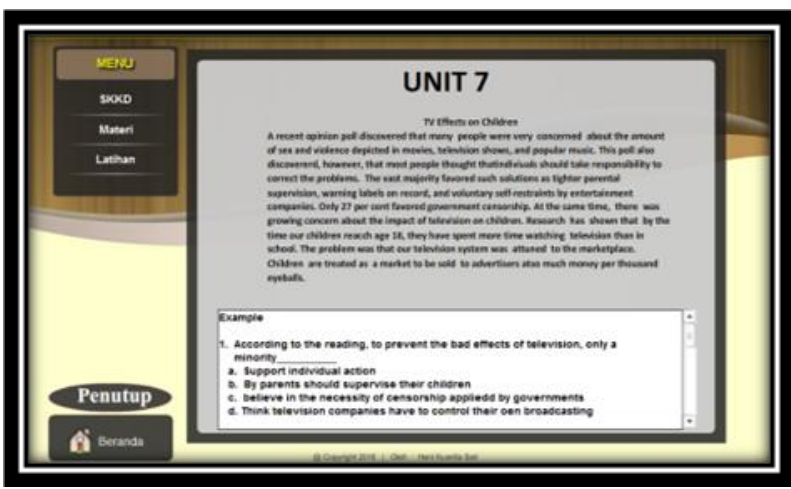

Gambar 11. Rancangan Materi Unit 7

Menu yang berisi Penjelasan Reading pada Materi Unit 7, terdapat menu materi di sisi kiri untuk kembali ke menu materi Unit 1 sampai dengan Unit 10 dan terdapat tombol Beranda untuk kembali ke menu Utama.

\section{Rancangan Materi Unit 8}

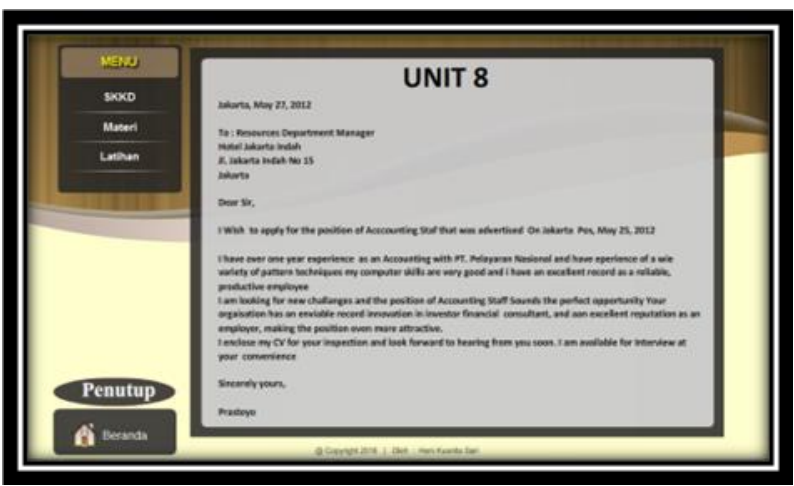

Gambar 12 Rancangan Materi Unit 8

Menu yang berisi Penjelasan Reading pada Materi Unit 8, terdapat menu materi di sisi kiri untuk kembali ke menu materi Unit 1 sampai dengan Unit 10 dan terdapat tombol Beranda untuk kembali ke menu Utama.

\section{Rancangan Materi Unit 9}

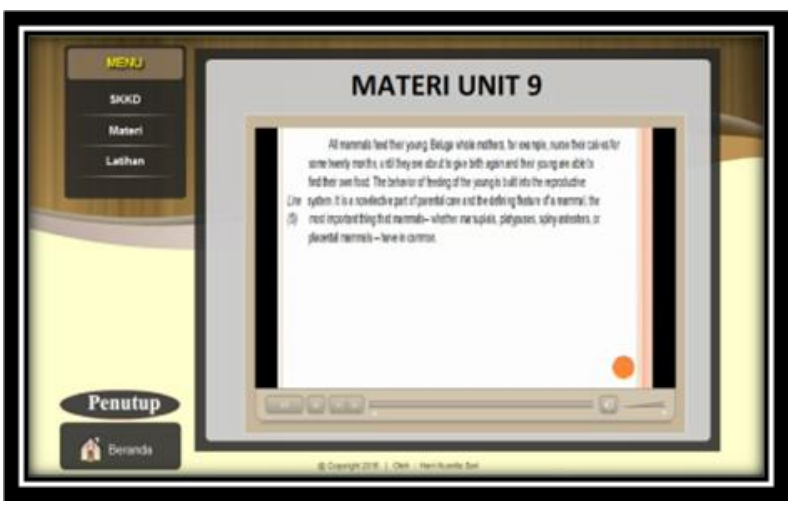

Gambar 13 Rancangan Materi Unit 9

Menu yang berisi penjelasan materi Listening Unit 9, terdapat tombol-tombol Pause,Play dan Stop. dan terdapat menu Materi disisi kiri penjelasan materi untuk kembali ke menu masing-masing unit 1 sampai dengan 10 dan terdapat tombol Beranda untuk kembali ke menu Utama.

\section{Rancangan Materi Unit 10}

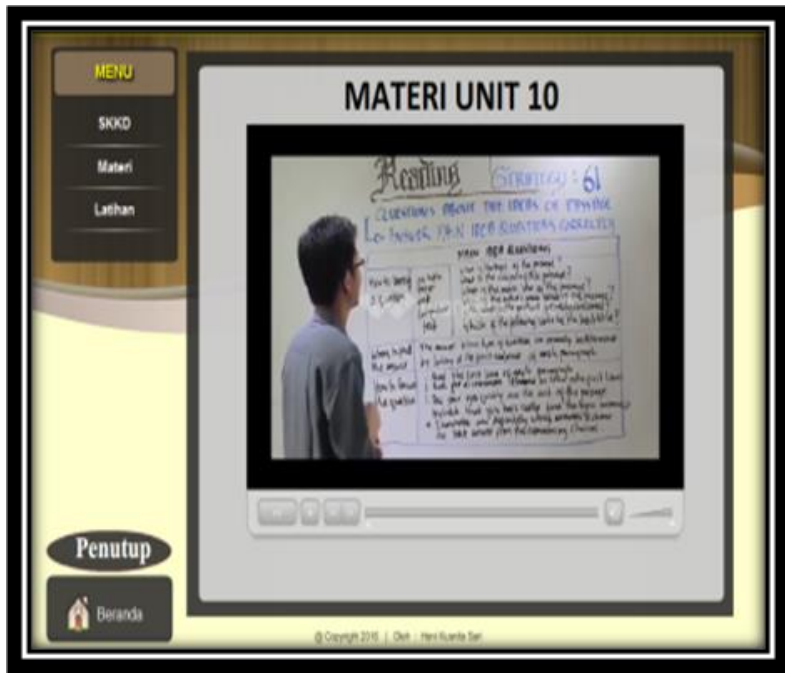

Gambar 14 Rancangan Materi Unit 10

Menu yang berisi penjelasan materi Listening Unit 9, terdapat tombol-tombol Pause, Play dan Stop. dan terdapat menu Materi disisi kiri penjelasan materi untuk kembali ke menu masing-masing unit 1 sampai dengan 10 dan terdapat tombol Beranda untuk kembali ke menu Utama.

\section{Rancangan Materi Latihan}

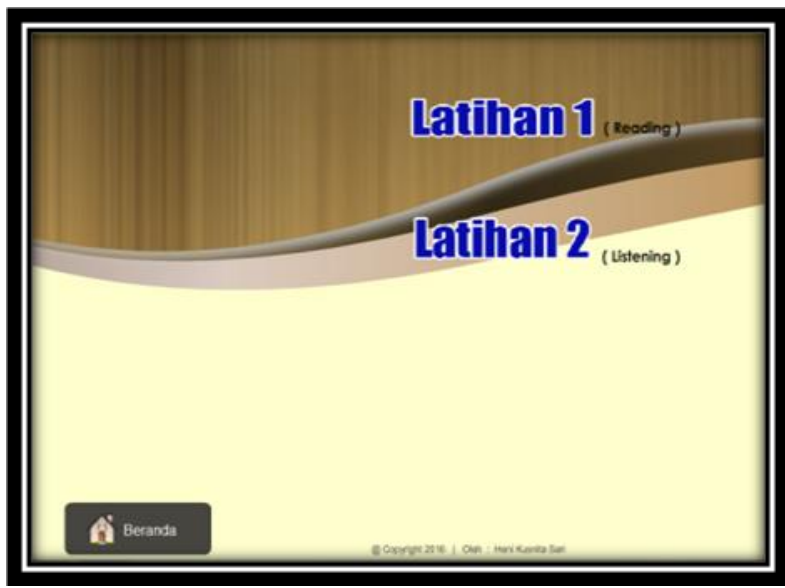

Gambar 15 Rancangan Menu Latihan

Menu Latihan yang trediri dari dua jenis latihan, yaitu Latihan 1 dan Latihan 2. Dimana latihan 1 berisi soal Reading dan Latihan 2 berisi soal Listening TOEFL dan terdapat tombol Beranda untuk kembali ke menu Utama.

\section{Menu Latihan 1}

ISSN $1858-2680$ 


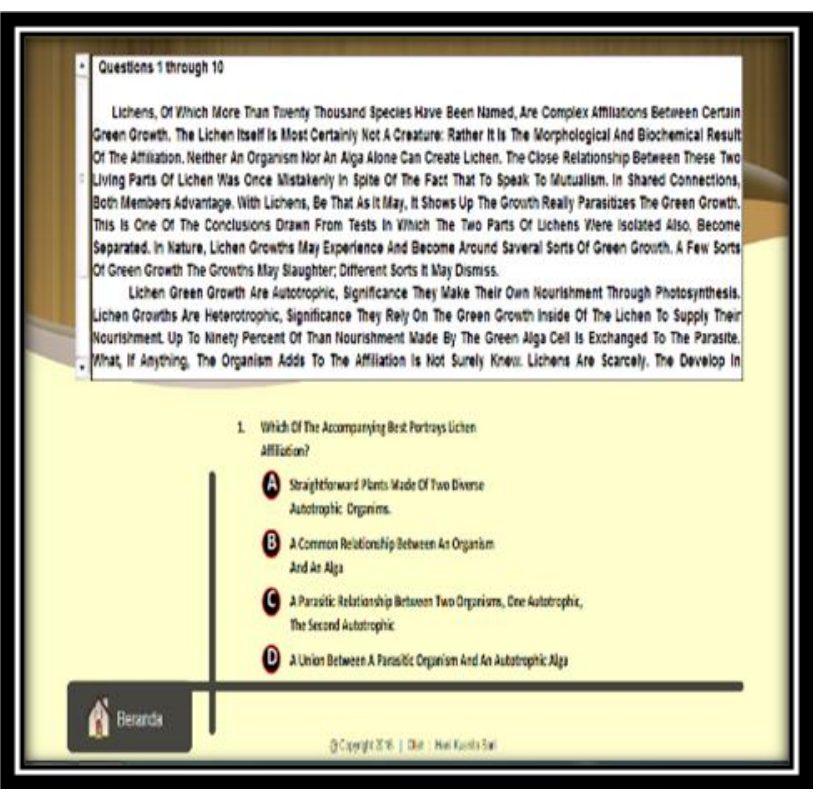

Gambar 16 Rancangan Menu Latihan

Menu Latihan 1 berisi soal-soal Reading terdiri dari 20 soal, dimasing-masing soal sudah ada option jawaban a, b, c dan d. jika benar maka option yang dipilih akan berubah warna dan ada tepuk tangan, jika jawaban salah maka akan berbunyi dengan nada yang salah diakhir soal nanti akan langsung ada jumlah skor yang diperoleh disisi kiri bawah ada tombol beranda untuk kembali ke menu Utama.

\section{Menu Evaluasi Latihan 1}

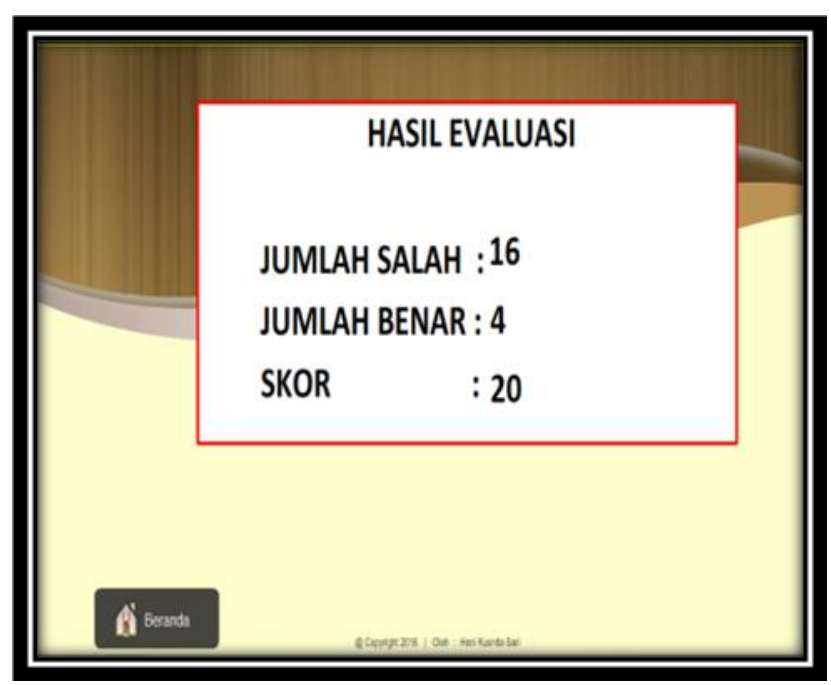

Gambar 17 Rancangan Menu Evaluasi Latihan

Menu Evaluasi Latihan berisi skor dari jumlah jawaban yang benar dan yang salah, disisi kiri bawah terdapat tombol Beranda untuk kembali ke menu Utama.

\section{Menu Latihan 2}

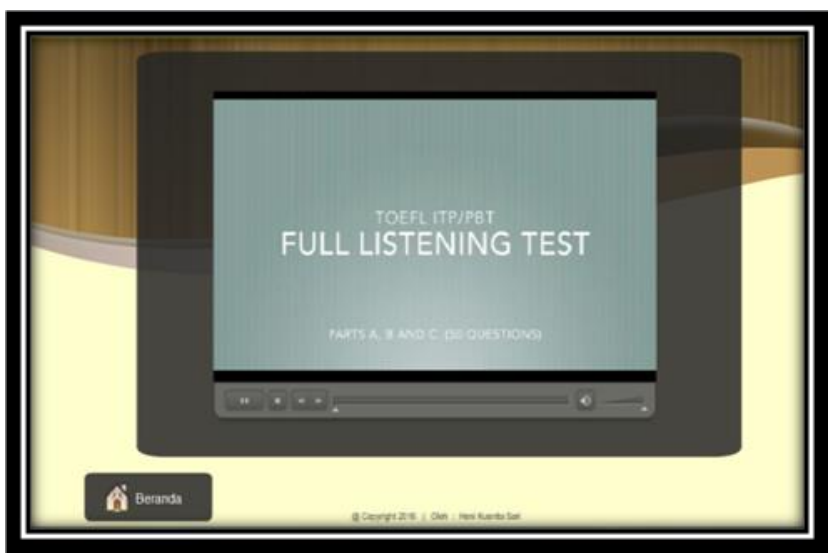

Gambar 18 Rancangan Menu Latihan 2

Menu Latihan 2 berisi video soal-soal Listening terdiri dari 30 soal, dimasing-masing soal sudah ada option jawaban a, b, c dan d. Disisi kiri bawah ada tombol beranda untuk kembali ke menu Utama.

\section{Penutup}

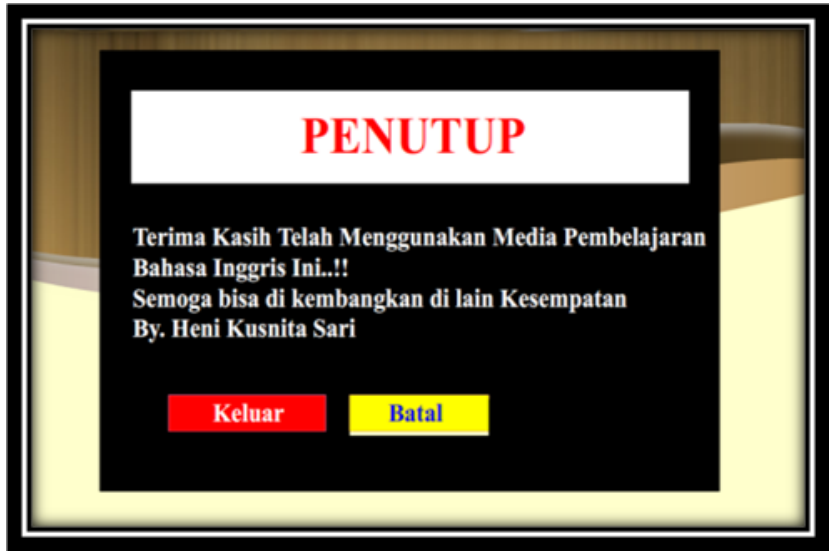

Gambar 19 Rancangan Menu Penutup.

\section{Pengujian Sistem}

Hasil akhir dari perancangan Media Pembelajaran Mata Kuliah Bahasa Inggris Pada FKIP Universitas Dehasen Bengkulu Menggunakan Macromedia Flash 8 diharapkan untuk dapat memudahkan mahasiswa dalam menyelesaikan pembelajaran, untuk itu maka dilakukan pengujian sistem (testing) terhadap perancangan sistem.

Perancangan dilakukan dengan mencoba menampilkan data-data soal yang disajikan kepada mahasiswa dan menjawab setiap materi pembelajarannya secara beraturan. Materi ini tidak dapat dilakukan secara acak karena sudah dirancang aplikasinya secara sistematis. 
Seiring dengan telah diungkapkan diatas, pengujian hasil perancangan Media Pembelajaran Mata Kuliah Bahasa Inggris Pada FKIP

Universitas Dehasen Bengkulu Menggunakan Macromedia Flash 8 selanjutnya didapatkan suatu hasil bahwa sistem ini dinyatakan final, karena sudah bebas dari erorr (debugging) sehinggah mendekati 100\% dan setiap layer dapat berjalan dengan baik.

Jika pengujian sistem materi dilakukan dengan melokalisir debug dan menentukan pada sistem operasi maka sistem dapat berjalan dengan baik, serta yang paling penting adalah software dinyatakan final fungsi utamanya tidak keluar dari aturan dan fungsi yang telah diterapkan. Pengujian melibatkan sebanyak 10 (sepuluh) orang dengan cara mengisi kuisioner pengujian. Terdapat 5 item pertanyaan yang diberikan 3 pilihan jawaban. Berikut table hasil pengujian Media Pembelajaran Mata Kuliah Bahasa Inggris Pada FKIP Universitas Dehasen Bengkulu Menggunakan Macromedia Flash 8 .

\section{KESIMPULAN}

Berdasarkan hasil dari pembahasan sebelumnya yakni mengenai bagaimana membuat Media Pembelajaran Pada FKIP Universitas Dehasen Bengkulu menggunakan Macro media Flash 8, adalah : Media Pembelajaran pada FKIP Universitas Dehasen Bengkulu dapat membuat mahasiswa lebih cerdas dan memudahkan Mahasiswa dalam menyelesaikan soal-soal setelah melakukan pembelajaran dalam waktu tertentu di ruangan kelas. Seorang Dosen tidak perlu menulis soal-soal materi pembelajaraannya dipapan tulis cukup dengan menampilkan dilayar lebar dengan menggunakan 1 buah Komputer/ Laptop dan satu buah Infokus dan Speaker.

Diharapkan agar FKIP Universitas Dehasen Bengkulu Program yang dapat diperbaiki diantaranya penggunaan sound agar lebih jelas, menggunakan background yang menarik supaya lebih atraktif.

\section{DAFTAR PUSTAKA}

[1].Daryanto. 2004. Keterampilan Dasar Pengoperasian

Komputer. Bandung: Yrama Widya. 400 halaman
[2].Deny Satria Wicaksono,et.al. (2011). Media Pembelajaran Fisika Interaktiv Bahasan Kapasitor

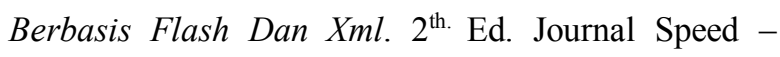
Sentra Penelitian Engineering dan Edukasi

[3].Erlina. 2010. Supermedia. Jakarta: Esis Galuh Puspita Ariputr. (2015). Pengembangan Aplikasi Android Untuk Mendukung Pembelajaran Listening BahasaInggris Kelas Xi Sma. $4^{\text {th }}$ Ed. Jurnal Penelitian Tindakan Kelas.

[4].Priyanto.2011. "Membuat Mobile Game Edukatif Dengan Flash”. Informatika Bandung

[5].Sukarno. 2008. "Easy Daily Conversation". Bangutapan: Jogjakarta

[6].Sutarman. 2009. "Pengantar Teknologi Informas"i. Yogyakarta : Bumi Aksara

[7].Yakub. (2012). "Pengantar Sistem Informasi". Yogyakarta: Graha Ilmu. 182 halaman 